\title{
Enhanced Rice Growth is Conferred by Increased Leaf ADP-Glucose Pyrophosphorylase Activity
}

\author{
Authors: Alanna J. Schlosser, John M. Martin, Brian S. \\ Beecher, and Michael J. Giroux
}

NOTICE: this is the author's version of a work that was accepted for publication in Journal of Plant Physiology \& Pathology. Changes resulting from the publishing process, such as peer review, editing, corrections, structural formatting, and other quality control mechanisms may not be reflected in this document. Changes may have been made to this work since it was submitted for publication. A definitive version was subsequently published in Journal of Plant Physiology \& Pathology, October 2014 DOI\# 10.4172/2329-955X.1000136

Schlosser, Alanna J., John M. Martin, Brian S. Beecher, and Michael J. Giroux. Enhanced Rice Growth is Conferred by Increased Leaf ADP-Glucose Pyrophosphorylase Activity. Journal of Plant Physiology \& Pathology. October 2014.

https://dx.doi.org/10.4172/2329-955X.1000136

Made available through Montana State University's ScholarWorks scholarworks.montana.edu 


\section{Enhanced Rice Growth is Conferred by Increased Leaf ADP-Glucose Pyrophosphorylase Activity}

Alanna J Schlosser, John M Martin, \& Michael Giroux: Department of Plant Sciences, Montana State University, Bozeman Montana
Brian S Beecher: USDA-GIPSA Technology and Science Division, Kansas City, Missouri

\begin{abstract}
Modification of leaf starch levels may be employed in attempts to increase cereal yield. Few studies have examined leaf starch as a plant biomass limiting factor. Here we test the hypothesis that rice plant productivity may be increased by increasing leaf starch. Starch biosynthesis is controlled by the heterotetrameric rate-limiting enzyme ADP-glucose pyrophosphorylase (AGPase). Rice variety Nipponbare was transformed with a modified form of the maize endosperm AGPase large subunit gene, Sh2r6hs, as well as with the small subunit gene, $B t 2$, under control of a rice RuBisCO small subunit promoter. RNA sequencing results indicated that Sh2r6hs and Bt2 transcript levels were each greater than 20 times that of the native genes. Increased total AGPase activity was correlated with higher leaf starch accumulation at the end of the day. Yield trials of $T_{1}$ derived homozygous plants indicate that increased leaf AGPase leads to a $29 \%$ increase in plant biomass under the conditions tested without changing the rate of photosynthesis while significantly reducing leaf transpiration and conductance. Additionally, functional annotation clustering of significantly up and down regulated transcripts reveals areas of protein metabolism, specifically protein biosynthesis, transport, and localization, that were altered in response to increased leaf starch. Together, these findings indicate plant growth is limited by native levels of leaf starch and that it is possible to increase plant yield via the starch biosynthesis pathway.
\end{abstract}

\section{Introduction}

Agronomic yield is a quantitative trait, highly impacted by the environment [1]. Productivity is reliant upon biochemical and physiological processes with underlying genetic control [2]. Grain yield is ultimately dependent upon photosynthesis, and thus upon photoassimilate production and efficient carbon allocation of assimilate to sinks which are developing or storage tissues $[3,4]$.
Growth potential of different plant organs is largely driven by production and flow of photoassimilates and nutrients inside the plant [3]. There have been many studies aimed at increasing yield by targeting increased production and storage of photoassimilates [5,6], the most common method being to increase activity of carbohydrate metabolic pathway enzymes in sink tissues such as seeds. For example, increased expression of ADP-glucose pyrophosphorylase in rice seeds is associated with increased seed yield [7], and over expression of a sucrose-phosphate synthase gene in potato tubers is associated with increased potato tuber yield [8].

The most important metabolic pathway involved in sink strength in developing seeds is starch biosynthesis. As the enzyme controlling the rate limiting step in starch biosynthesis, ADP-glucose pyrophosphorylase (AGPase) has received considerable attention [9]. In plants, AGPase is a heterotetramer consisting of two large and two small subunits $[10,11]$. In the presence of ATP, AGPase acts upon the substrates glucose 1-phosphate and ATP to produce ADP-glucose [12]. ADP-glucose pyrophosphorylase is also an allosteric enzyme; the positive regulator is 3-PGA and the negative regulator is inorganic orthophosphate $(\mathrm{Pi})[10,11]$. Additionally, there are seed and leaf specific isoforms of AGPase [13-16]. Cereal endosperm AGPases lack transit peptides and thus there are both seed (endosperm cytoplasm localized) and leaf specific (chloroplast localized) forms of both the large and small AGPase subunits [13,17].

Several studies have focused on increasing seed sink strength by over expressing AGPase in seeds. In wheat [18,19] and rice [7] increased expression of a deregulated form of the maize large subunit of AGPase under an endosperm-specific promoter led to increased seed weight per plant and higher plant biomass. Increases in both seed yield and plant biomass, such that harvest index remained unchanged, indicated up-regulation of metabolism in both sink and source tissues. However, this complex enhanced yield phenotype was not observed under field conditions [20].

A less studied area involving carbon metabolism has been leaf starch as a plant productivity limiting factor. A study in rice [21] investigated how a transposon derived leaf-specific AGPase knockout mutation impacted plant productivity. Although the rice mutation resulted in near absence of leaf starch, no differences in plant growth or yield were observed under low light growth chamber conditions [21]. A similar mutation, agps-m1, was reported in maize in which the leaves lacked leaf starch due to a transposon insertion in the leaf AGPase small subunit [22]. We tested the impact of the lack of leaf starch upon maize productivity by examining the growth of agps-m1 plants under field conditions. The agps- $m 1$ plants flowered two days later, were five $\mathrm{cm}$ shorter, and had 30\% lower seed yield relative to wild type leaf starch isogenic plants [23], indicating the importance of leaf starch under field conditions. In addition to reverse genetic studies where leaf starch has been removed, other studies have examined whether native leaf starch levels limit plant growth by overexpressing AGPase in leaves. Expression of a modified potato AGPase large subunit, upreg1 [24], in lettuce increased fresh weight and starch content at eight weeks after germination [25]. However, the lettuce plants were not taken to maturity thus plant development and seed yield data were not reported. An additional study in rice utilizing leaf 
specific over expression of upreg1 showed a trend of increased seed yield in comparison to the varietal control [26].

In this study, we have tested the role of leaf AGPase in rice productivity by over expressing AGPase in leaves. Unlike the approach used in [26], rice was transformed with maize endosperm AGPase large and small subunits modified to have the rice leaf AGPase chloroplast transit peptide. The AGPase transgenes were under the control of the native rice RuBisCO small subunit promoter. Under the conditions tested, over-expression of both AGPase subunits lead to significantly increased biomass without changing photosynthetic rates while significantly reducing leaf transpiration and conductance. Global changes in transcript levels provide insight into molecular processes associated with increased starch biosynthesis.

\section{Materials and Methods}

\section{Plasmid construct used for transformation}

The pRBCSh2Bt2 plasmid construct was used for transformation (Figure 1). The vector made use of the pTF101.1 binary vector [27] that contains the aadA gene, for bacterial selection of spectinomycin resistance, and the phosphinothricin acetyl transferase (bar) gene controlled by the cauliflower mosaic virus $35 \mathrm{~S}$ promoter (2x CaMV $35 \mathrm{~S}$ ) and the nopaline synthase (NOS) terminator. The bar gene confers resistance to the herbicide glufosinate (Bayer Crop Science, Kansas City, MO). The AGPase subunits were the large and small subunits of maize endosperm, Sh2 and Bt2, respectively. The wild type Sh2 coding sequence [28] was modified as previously described [29]. The resulting Sh2r6hs coding sequence contains two alterations. The $(r 6)$ modification is a two amino acid insertion conferring reduced AGPase phosphate inhibition in vitro [30]. The hs alteration is a single amino acid substitution that confers more stable AGPase subunit interactions in vitro [31]. The wild type $B t 2$ coding sequence [32] was also included along with the tobacco RB7 matrix attachment region sequence (MARS) [33] which was positioned between the NOS terminator of the Sh2r6hs coding sequence and the promoter of the Bt2 gene. Additionally, both the Sh2r6hs and Bt2 coding sequences were modified to include a $141 \mathrm{bp}$ segment encoding a rice leaf AGPase chloroplast specific signal peptide. Sh2r6hs and Bt2 were under control of the native rice $\mathrm{RuBisCO}$ small subunit promoter $(R B C)$

\section{Production of transgenic plants and preliminary analysis of transgenic lines}

Construct pRBCSh2Bt2 was introduced into rice japonica variety Nipponbare calli at the Iowa State University Plant Transformation Facility via an Agrobacterium-mediated transformation system [34]. The initial $\mathrm{T}_{0}$ plantlets, hemizygous for the transgenes, were advanced to maturity in growth chambers with conditions set at $28^{\circ} \mathrm{C}$ day $/ 22^{\circ} \mathrm{C}$ night with a $12 \mathrm{~h}$ photoperiod. Plants were allowed to self-pollinate and mature and were harvested 60 days after flowering. $T_{1}$ plants segregating 1:2:1 for the transgenes were advanced and seed was harvested.

For selection of homozygotes $16 \mathrm{~T}_{2}$ seeds from each $\mathrm{T}_{1}$ plant were planted in Sunshine soilless mix \# 1 (Sun Gro Horticulture, Vancouver, British Columbia, Canada) and grown to the 2-3 leaf stage. The seedlings were then sprayed with a solution of $0.1 \%$ glufosinate until runoff and scored for herbicide resistance or susceptibility after 7 days. $\mathrm{T}_{1}$ plants producing 12 or more consecutive resistant plants were

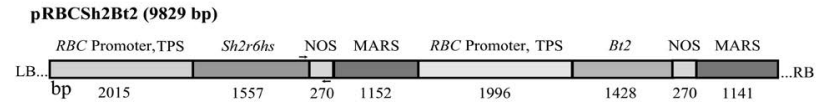

Figure 1: Structure of the pRBCSh2r6hs AGPase transgenes. The Sh2r6hs and $B t 2$ coding sequences were combined into the pTF101.1 binary vector under control of the rice RuBisCO small subunit $(R B C)$ promoter and the NOSterminator. The positions of the tobacco RB7 matrix attachment region sequence (MARS) and transit peptide sequences (TPS)are noted. Arrows represent position of PCR primers.

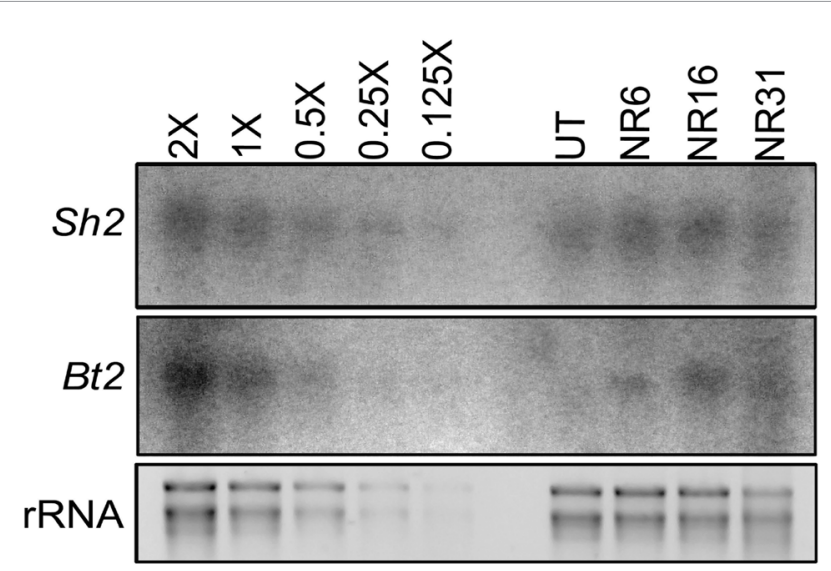

Figure 2: Northern blot analysis of pRBCSh2Bt2 transgenic rice lines and untransformed Nipponbare (UT). A loading curve for NR16 was included to quantify expression of the transgenes in lines expressing Sh2r6hs and Bt2. Expression of NR16 at $1 \mathrm{X}$ represents $5 \mu \mathrm{g}$ total RNA.

classified as homozygous for the presence of the transgenes. Plants producing 4 or more consecutive susceptible seedlings were classified as homozygous for the absence of the transgenes. Three events with high over expression of the transgenes were chosen for further study. $\mathrm{T}_{1}$ derived homozygous transgenes positive and negative plants $\left(\mathrm{T}_{1 \cdot 2}\right.$ and $\mathrm{T}_{1: 3}$ ) with over expression of both AGPase transgenes were used for further study, such that negative and positive sister lines were derived from the same $\mathrm{T}_{1}$ source material within each event.

Genomic DNA was isolated and PCR was conducted on $\mathrm{T}_{1}$ glufosinate resistant and susceptible plants to confirm that the $\mathrm{Sh} 2$ and $\mathrm{Bt} 2$ transgenes co-segregated with glufosinate resistance. PCR reactions were conducted using an upstream PCR primer, 5'-ACCATCAACGATGGGTCTGT-3', which hybridizes to the Sh2r6hs cDNA beginning 24 base pairs upstream of the stop codon, and downstream primer, 5'-TTGCGCGCTATATTTTGTTTT-3', complementary to base pairs 204-224 of the NOS terminator. This primer pair produces a 210 base pair amplified product using GoTaq DNA polymerase (Promega, Madison, WI, USA). PCR parameters were as follows: $94^{\circ} \mathrm{C}$ for $5 \mathrm{~min}, 35 \mathrm{cycles}$ of $94^{\circ} \mathrm{C} 30 \mathrm{sec}, 51^{\circ} \mathrm{C} 30 \mathrm{sec}$, $72^{\circ} \mathrm{C} 45 \mathrm{sec}$, followed by $72^{\circ} \mathrm{C}$ for $7 \mathrm{~min}$. Co-segregation of the AGPase transgenes and glufosinate resistance was confirmed for all events.

\section{Transgene expression analysis}

Tissue was collected near the end of the day ( $1.5 \mathrm{hr}$ pre-lights off) from three individual $T_{1: 3}$ plants at anthesis. The terminal 7.5 $\mathrm{cm}$ of a leaf, located two leaves down from the tallest panicle, was collected from each plant and bulked within genotype. Tissue was 
directly frozen in liquid $\mathrm{N}_{2}$, ground into a powder, and total RNA was extracted using an RNeasy Mini Kit (Qiagen, Valencia, CA) following the manufacturer's instructions. Total RNA was quantified on a Bioanalyzer (Agilent Technologies, Santa Clara, CA) and electrophoresed on formaldehyde containing agarose gels with an equal portion of each sample electrophoresed on an ethidium bromide stained agarose gel without formaldehyde to ensure equal formaldehyde gel loading. RNA was transferred to a Hybond-XL nylon membrane (Amersham Biosciences, Uppsala, Sweden), probed with ${ }^{32} \mathrm{P}$-random primer labeled (Takara Bio Inc., Otsu, Shiga, Japan) Sh 2 and Bt 2 coding sequences, and hybridized overnight at $65{ }^{\circ} \mathrm{C}$ in a solution that was $7 \%$ SDS and $0.5 \mathrm{M}$ sodium phosphate, $\mathrm{pH}$ 7.2. Hybridized membranes were washed five times in $2 \mathrm{X}$ sodium chloride / sodium phosphate / EDTA (SSPE), from a 20X SSPE stock with concentration of $3.0 \mathrm{M} \mathrm{NaCl}, 0.2 \mathrm{M} \mathrm{NaH}_{2} \mathrm{PO}_{4}$ and $0.02 \mathrm{M}$ EDTA, pH 7.3 at $65^{\circ} \mathrm{C}$. Membranes were washed an additional two times in $0.2 \mathrm{X}$ SSPE at $65^{\circ} \mathrm{C}$ and dried at $37^{\circ} \mathrm{C}$ for $40 \mathrm{~min}$. Hybridized membranes were exposed to Kodak Biomax MS film (Rochester, NY) with an intensifying screen at $-80^{\circ} \mathrm{C}$.

Whole transcriptome shotgun sequencing (RNA-seq) technology was employed to determine transgene and genome wide expression levels for NR16 and NR31. Sh2r6hs expression of samples utilized in RNA-seq was confirmed with northern blot analysis (data not shown). Leaf tissue from randomly selected AGPase transgene homozygous positive and negative $T_{1: 3}$ plants were collected at the 3-4 leaf stage for RNA extraction. The terminal $3 \mathrm{~cm}$ of the uppermost erect leaf at 30 days post emergence was collected and immediately frozen. Three biological replicates were collected per AGPase genotype, each consisting of two plant bulks of harvested leaf tissue from 2 randomly selected plants within each genotype. Tissue was ground in liquid $\mathrm{N}_{2}$ and total RNA extracted as described above. For RNA-seq analysis, $1 \mu \mathrm{g}$ of total RNA was used for creation of cDNA libraries using TruSeq RNA-SEQ library kits (Illumina Inc., San Diego, CA) with 6 bp molecular identification tags added for multiplexing. Amplicons from cDNA libraries were sequenced as single $50 \mathrm{bp}$ reads using an Illumina High Scan-SQ platform. RNA-seq analysis was carried out with QSeq and ArrayStar v4.1 (DNASTAR, Madison, WI). Sequence data were imported and genes of interest selected for analysis with the match settings set to $100 \%$ for at least $40 \mathrm{bp}$ and all other settings left at default with reads per kilobase of exon model per million mapped reads (RPKM) normalization [35]. Resultant expression data were converted to linear counts and normalized to eukaryotic elongation factor 1-alpha $(e E l-1 \alpha)$. Two-tailed $t$-tests were performed to determine if significant changes in expression existed between positive and negative AGPase transgene genotypes.

The most highly up (54) or down-regulated (84) genes throughout the genome $(P$-value $<0.01)$ were identified using ArrayStar v4.1 (DNASTAR, Madison, WI). Functional annotation clustering of these genes was performed using the DAVID Bioinformatics Resources Functional Annotation tool [36].

\section{AGPase activity assays}

Assays were performed on leaf tissue harvested at the four leaf stage at mid-day. The terminal $3 \mathrm{~cm}$ of the uppermost erect leaf was collected from three randomly selected $\mathrm{T}_{1: 3}$ plants within each genotype and combined into homozygous transgenes positive or negative bulks with three biological replicates and directly frozen. Leaf tissue was then ground to a powder without allowing samples to thaw and $5 \mu \mathrm{mg}{ }^{-1}$ fresh weight leaf tissue of extraction buffer with a concentration of $80 \mathrm{mM}$ HEPES, $1 \mathrm{mM}$ EDTA, $0.1 \mathrm{mM}$ DTT, 2 $\mathrm{mM} \mathrm{MgCl}{ }_{2}$ and $10 \mu \mathrm{ml}^{-1}$ Halt protease inhibitor (ThermoScientific, Rockford, IL) was added to samples. Samples were vortexed and centrifuged at $13,000 \mathrm{~g}$ for $2 \mathrm{~min}$ then $5 \mu \mathrm{l}$ of supernatant was transferred to new tubes containing $20 \mu$ extraction buffer with $2 \mathrm{mM}$ ATP, $2 \mathrm{mM}$ glucose-1-phosphate, $0,0.5,2$, or $4 \mathrm{mM}$ Pi and contained $1 \mathrm{nCi}{ }^{14} \mathrm{C}$-labeled glucose-1-phosphate (PerkinElmer, Boston, MA, USA). Reactions were incubated at $37^{\circ} \mathrm{C}$ for $10 \mathrm{~min}$, boiled for $5 \mathrm{~min}$ and then treated with $3 \mathrm{U}$ alkaline phosphatase (Promega, Madison, WI, USA). Reactions were transferred to DE81 disks (Whatman, Buckinghamshire, UK), which were then washed four times in $\mathrm{H}_{2} \mathrm{O}$ and dried. Total activity (measured in counts per minute) was measured with a Tri-Carb 1905AB/LA liquid scintillation counter (Packard BioScience, Meriden, CT). Enzyme activity $\left(\mathrm{min}^{-1} \mathrm{mg}^{-1} \mathrm{FW}\right)$ was calculated as in [18] substituting $\mathrm{mg}^{-1} \mathrm{FW}$ for $\mathrm{mg}^{-1}$ total protein (Figure 3A).

\section{Leaf starch quantification}

Leaf tissue was collected near the end of the day ( $1.5 \mathrm{hr}$ pre-lights off) from the largest fully expanded leaf at the four leaf stage. The terminal $10 \mathrm{~cm}$ was collected and bulked between two samples. Three biological replicates were collected and tissue was ground. Leaf starch was extracted from $20 \mathrm{mg}$ of ground powder according to [37]. Free glucose was removed from ground leaf powder by incubating in $80 \% \mathrm{EtOH}$ for $3 \mathrm{~min}$ at $80^{\circ} \mathrm{C}$. This step was repeated twice. Extracted starch pellets were resuspended in 1:1 $\mathrm{dH}_{2} \mathrm{O}: 200 \mathrm{mM}$ sodium acetate ( $\mathrm{pH} 4.8$ ) and starch was digested with $0.2 \mathrm{U} \alpha$-amylase and $0.6 \mathrm{U}$ amyloglucosidase $\mathrm{mg}^{-1} \mathrm{DW}$. Samples were assayed according to [38] using NADP in place of NAD. Starch concentration was determined by including a standard curve in assays prepared with known amounts of wheat starch (Azure Farm, Dufur, OR).

\section{Photosynthetic carbon fixation measurements}

Measurements of photosynthetic rates were conducted as in [23]. The CI-340 machine (CID, Camas, WA) was zeroed using ambient $\mathrm{CO}_{2}$ with the value set at $389 \mathrm{ppm}$ (http://co2now.org, accessed October 11, 2011). Measurements were conducted over the course of the photoperiod on the uppermost flag leaf of $\mathrm{T}_{1: 3}$ plants at 1-3 days after flowering (DAF). Values presented are the means of all data collected from $\mathrm{T}_{1: 3}$ plants grown in a paired and randomized growth chamber yield trial though out the photoperiod.

\section{Analysis of yield phenotype parameters}

$\mathrm{T}_{1: 3}$ seed was pooled from parent plants into homozygous positive or negative bulks. Seed was de-hulled and soaked in deionized water overnight. Five seeds were planted per $7.5 \times 10 \times 13 \mathrm{~cm}$ pot and direct seeded into Profile Greens Grade calcified clay (Profile Products LLC, Buffalo Grove, IL) containing $4.93 \mathrm{cc}$ each of 30:10:10 Osmocote (The Scotts Company LLC, Marysville, $\mathrm{OH})$ and 1:0:1 Ironite $(4.5 \% \mathrm{Fe})$ Mineral Supplement (Ironite, Walnut Creek, CA). Pots were placed in an incubator under artificial lights delivering 100 photosynthetically active radiation (PAR) and incubated at $25^{\circ} \mathrm{C}$ until plants were approx. $15 \mathrm{~cm}$ tall. Pots were thinned to two plants and homozygous positive and negative plants were paired and randomized within each genotype for a sample size of $n=12-15$. Plants were moved to a growth chamber with a $24^{\circ} \mathrm{C}$ day $/ 22^{\circ} \mathrm{C}$ night temperature regime and a $12 \mathrm{hr}$ photoperiod. Artificial lighting provided $600 \mu \mathrm{E} \mathrm{m}^{-2} \mathrm{~s}^{-1} \mathrm{PAR}$ at canopy height. Day temperature was increased to $28^{\circ} \mathrm{C}$ at the five tiller 
A

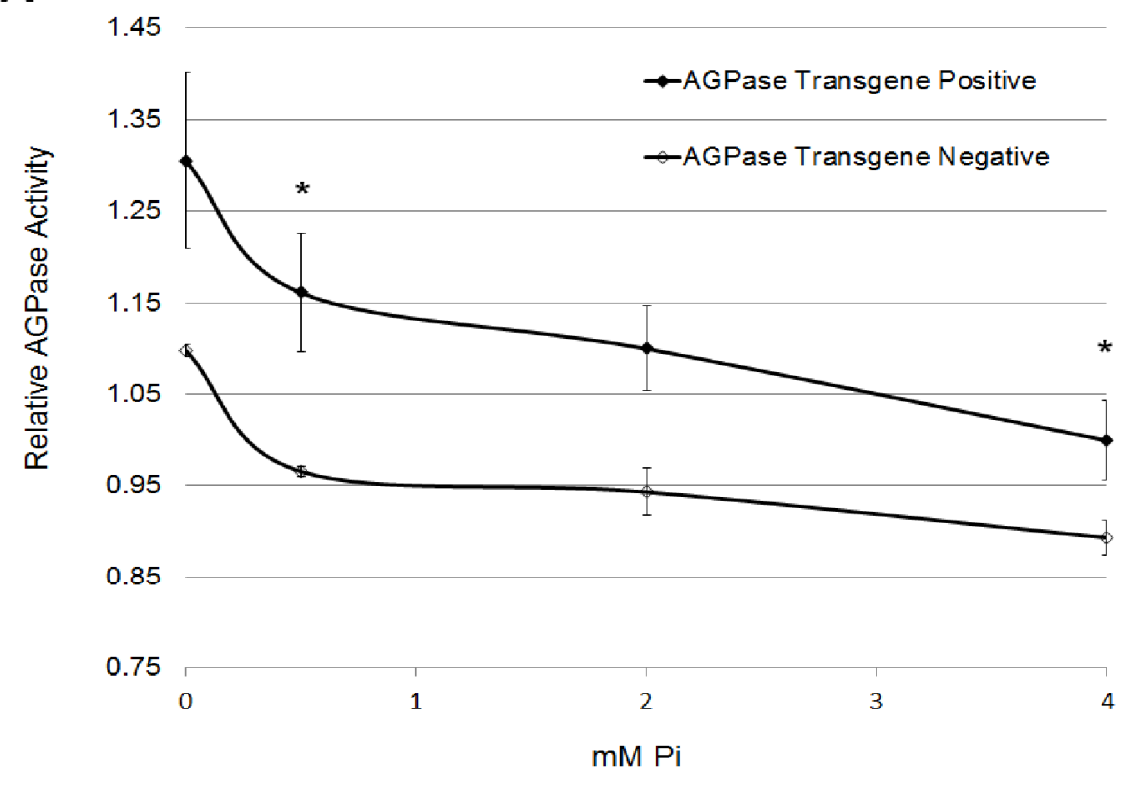

B

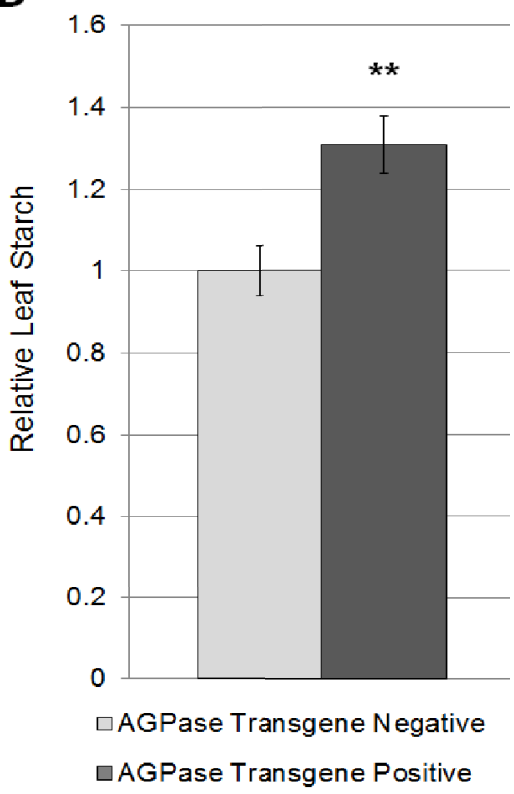

Figure 3: Leaf tissue was collected and analyzed for AGPase activity (A) and leaf starch (B). (A)AGPase activity of three transgenic rice lines in response to phosphate inhibition. AGPase activity (nmol ADP glucose $\mathrm{mg}^{-1} \mathrm{FW}$ ) was measured on $\mathrm{T}_{3}$ flag leaf tissue bulked from three homozygous transgene positive and negative plants with three biological replicates. Mean values were obtained when $5 \mu$ l solubilized protein was added to $20 \mu l$ extraction buffer containing 2 mM ATP, Glc-1-P, and 3-PGA and 0, 0.5, 2, or $4 \mathrm{mM}$ Pi respectively.(B) Starch quantification from leaves at the end of the day." Indicate significant differences of $p$-value $<0.5$ or 0.01 respectively using a one-tailed $t$-test with the hypothesis that transgene positive lines would have increased AGPase activity in leaves.

stage and pots were thinned to one plant. Plants were bottom irrigated daily in tubs delivering 57 ppm N prepared using Peters Excel 15-515 Cal-Mag (Everris, Marysville, OH) [39]. Plants were allowed to self-pollinate and watered daily until 60 days after flowering. Mature plants were harvested, and biomass was weighed after one week in a $37^{\circ} \mathrm{C}$ drying chamber. Biomass and all yield parameters were recorded on a per plant basis. Leaf chlorophyll values were collected using a SPAD-502 chlorophyll meter (Minolta Co., LTD, Japan) and represent the mean of five leaves per plant. Height was measured to the base of the tallest panicle.

\section{Analysis of results}

Transgene positive and negative mean values were compared using a two-tailed, two independent sample $t$ statistic or a one-tailed, two independent sample $t$ statistic with the hypothesis that transgene positive plants would be more vigorous than transgene negative plants. For the yield trials, positive/negative ratio was calculated between each genotypic pair. Standard error is representative of the ratios of each pair within the trial.

\section{Results}

\section{Analysis of transgenic lines}

The rice variety Nipponbare was transformed with Sh2r6hs and $B t 2$ under the control of the $R B C$ promoter (Figure 1). $\mathrm{T}_{1}$ seed from glufosinate resistant $\mathrm{T}_{0}$ transgenic rice lines were obtained through Agrobacterium mediated transformation. Lines NR6, NR16, and NR31 were advanced for further study as they each had expression of both AGP transgenes (Figure 2).

PCR specific to the Sh2r6hs and Bt2 transgenes along with
Table 1: Transgene analysis of three $T_{1}$ rice lines segregating $3: 1$ for over expression of Sh2r6hs and Bt2.

\begin{tabular}{|c|c|c|c|}
\hline Transgenic Event & Progeny Test $^{\mathbf{a}}$ & Chi-Square Value & P-value \\
\hline NR6 & $10 / 3$ & 0.03 & 0.87 \\
\hline NR16 & $9 / 2$ & 0.27 & 0.60 \\
\hline NR31 & $16 / 2$ & 1.85 & 0.17 \\
\hline
\end{tabular}

aNumber of $T_{1}$ progeny positive/negative for Sh2r6hs. Progeny tests consisted of herbicide resistance screening of each plant with $0.1 \%$ glufosinate along with PCR for Sh2r6hs. In each event the herbicide resistance marker and AGP transgene co-segregated.

herbicide screening of $\mathrm{T}_{1: 2}$ plants indicate that the bar transgene and the Sh2r6hs transgene co-integrated, as all plants PCR positive for Shr6hs also showed resistance to $0.1 \%$ glufosinate with all Sh $2 r 6 h s$ PCR negative plants also glufosinate susceptible (Table 1). Chisquare analysis is consistent with integration of the transgenes at a single locus in each of the three events (Table 1).

\section{Expression analysis}

Northern blot and RNA Seq analysis indicate Bt2 is expressed at a higher level than Sh2r6hs (Table 2). The high homology between native genes and transgenes was apparent in the northern blot signal associated with the untransformed control when probed with Sh2. Staining of agarose gel fractionated rRNA with ethidium bromide indicated similar loading between lanes. Northern blot analysis revealed similar over expression levels across events (Figure 2), therefore NR16 and NR31 were selected as representatives for RNA sequencing.

Using next generation sequencing technology, over 150 million reads were obtained for the twelve samples ( 3 biological reps of two 
Table 2: RNA-seq expression data for genes of interest and housekeeping genes in positive and negative plants transformed with AGPase.

\begin{tabular}{|c|c|c|c|c|c|c|c|}
\hline $\begin{array}{c}\text { GenBank Accession } \\
\text { no. }\end{array}$ & Protein & Gene & $\begin{array}{l}\text { Predominantly } \\
\text { expressed tissue }\end{array}$ & $\begin{array}{l}\text { AGPase transgene } \\
\text { negative average }\end{array}$ & $\begin{array}{l}\text { AGPase transgene } \\
\text { positive average }^{\text {a }}\end{array}$ & Pos/neg fold & $P$-value ${ }^{\text {b }}$ \\
\hline \multicolumn{8}{|l|}{ Transgenes } \\
\hline NM_001127632 & Shrunken2 & Sh2 & Maize endosperm & $20.3 \pm 2.9$ & $67,506 \pm 9,269$ & NA & \\
\hline AF330035 & Brittle2 & $B t 2$ & Maize endosperm & $28.9 \pm 4.2$ & $98,097 \pm 18,036$ & NA & \\
\hline \multicolumn{8}{|l|}{ Starch Biosynthesis ${ }^{c}$} \\
\hline AK100910 & $\begin{array}{l}\text { ADP-glucose } \\
\text { pyrophosphorylase large } \\
\text { subunit }\end{array}$ & $A G P L 1$ & Leaf sheath & $35.2 \pm 6.9$ & $27.2 \pm 5.1$ & 0.77 & 0.36 \\
\hline AK071497 & & $A G P L 2$ & Endosperm & $264 \pm 35.5$ & $323.2 \pm 36.6$ & 1.23 & 0.39 \\
\hline AK069296 & & $A G P L 3^{\mathrm{h}}$ & Leaf tissue & $2,988 \pm 156$ & $3,191.4 \pm 164.5$ & 1.07 & 0.45 \\
\hline AK121036 & & AGPL4 & Roots & $60.7 \pm 6.0$ & $55.9 \pm 6.8$ & 0.92 & 0.69 \\
\hline AK073146 & $\begin{array}{l}\text { ADP-glucose } \\
\text { pyrophosphorylase small } \\
\text { subunit }\end{array}$ & AGPS1 & Leaf sheaths & $101 \pm 13.8$ & $95.8 \pm 12.4$ & 0.95 & 0.85 \\
\hline AK071826 & & AGPS2ai & Leaf tissue & $857 \pm 96.4$ & $764 \pm 101$ & 0.89 & 0.18 \\
\hline AK103906 & & $A G P S 2 b$ & Endosperm & $2,555 \pm 156$ & $2,167 \pm 282$ & 0.85 & 0.34 \\
\hline AK109458 & Starch synthase (soluble) & SS1 & Endosperm & $499 \pm 26.2$ & $552 \pm 58.6$ & 1.11 & 0.40 \\
\hline AK101978 & & sSlla & Endosperm & - & - & & \\
\hline AK066446 & & SSIIb & Leaf tissue & $1,498 \pm 86.8$ & $1,876 \pm 117$ & 1.25 & 0.02 \\
\hline AK072339 & & SSIIc & Leaf tissue and roots & $122 \pm 8.7$ & $108 \pm 4.6$ & 0.89 & 0.08 \\
\hline AK061604 & & SSIIIa & Endosperm & - & - & & \\
\hline AK122098 & & SSIIIb & Leaf tissue & $1,963 \pm 130$ & $1,991 \pm 114$ & 1.01 & 0.86 \\
\hline AK067577 & & SSIVb & Leaf tissue & $171 \pm 18.5$ & $182 \pm 14.5$ & 1.07 & 0.64 \\
\hline AK070431 & $\begin{array}{l}\text { Starch synthase (granule } \\
\text { bound) }\end{array}$ & GBSSI & Endosperm & $25.2 \pm 5.3$ & $36.8 \pm 6.0$ & 1.46 & 0.25 \\
\hline AK067654 & & GBSSII & Leaf tissue & $10,938 \pm 775$ & $12,556 \pm 702$ & 1.15 & 0.20 \\
\hline AK065121 & Branching enzyme & BEI & Endosperm & $857 \pm 70.4$ & $945 \pm 81.5$ & 1.10 & 0.54 \\
\hline AB023498 & & BElla & Leaf tissue & $3,195 \pm 211$ & $3,527 \pm 152$ & 1.10 & 0.25 \\
\hline D16201 & & RICBCE3 & Endosperm & $33.0 \pm 5.2$ & $34.2 \pm 5.4$ & 1.04 & 0.90 \\
\hline AK060577 & $\begin{array}{l}\text { Glucose 6-phosphate/ } \\
\text { phosphate translocator }\end{array}$ & GPT1 & Endosperm & $287 \pm 9.1$ & $353.5 \pm 28.8$ & 1.23 & 0.04 \\
\hline AK059906 & & GPT2 & Leaf tissue & $831 \pm 138$ & $824 \pm 106$ & 0.99 & 0.97 \\
\hline \multicolumn{8}{|c|}{ Photosynthesis $^{d}$ and Carbon Fixation ${ }^{e}$} \\
\hline AY445627 & RuBisCO small subunit & $R b c S$ & Leaf tissue & $600,007 \pm 33217$ & $640,394 \pm 7820$ & 1.07 & 0.66 \\
\hline D00207 & RuBisCO large subunit & $R b c L$ & Leaf tissue & $1,047 \pm 128$ & $2,693 \pm 1630$ & 2.57 & 0.33 \\
\hline GQ848049 & $\begin{array}{l}\text { Glyceraldehyde-3-phosphate } \\
\text { dehydrogenase }\end{array}$ & GAPDH & Leaf tissue & $3,208 \pm 86.6$ & $3,287 \pm 234$ & 1.02 & 0.79 \\
\hline NM_001070312 & Triose-phosphate isomerase & TIM & Leaf tissue & $11,878 \pm 1160$ & $13,404 \pm 1145$ & 1.13 & 0.28 \\
\hline NM_001054360 & Phosphoribulokinase & PRK & Leaf tissue & $70,575 \pm 3820$ & $77,490 \pm 3967$ & 1.10 & 0.21 \\
\hline D87819 & Sucrose Transporter & SUT1 & Above ground tissue & $171 \pm 9.8$ & $191 \pm 40.9$ & 1.12 & 0.67 \\
\hline AB091672 & & SUT2 & All tissue & $770 \pm 33.0$ & $754 \pm 42.6$ & 0.98 & 0.83 \\
\hline AB071809 & & SUT3 & Primarily sink leaves & - & - & & \\
\hline AB091673 & & SUT4 & Sink leaves & $126 \pm 6.8$ & $133 \pm 11.0$ & 1.06 & 0.59 \\
\hline AB091674 & & SUT5 & Primarily sink leaves & - & - & & \\
\hline \multicolumn{8}{|l|}{ Nitrogen Metabolism ${ }^{f}$} \\
\hline NM_001060668 & Glutamine synthetase & GS2 & Leaf tissue & $41,405 \pm 1941$ & $45,473 \pm 3513$ & 1.10 & 0.30 \\
\hline AJ132280 & $\begin{array}{l}\text { Ferredoxin-dependant } \\
\text { glutamate synthase }\end{array}$ & $F d-G O G A T$ & Leaf tissue & $5,152 \pm 648$ & $5,160 \pm 801$ & 1.00 & 0.99 \\
\hline NM_001059992 & Glutamate dehydrogenase2 & $G D H 2$ & Leaf tissue & $60.7 \pm 5.3$ & $60.5 \pm 9.2$ & 1.00 & 0.990 \\
\hline \multicolumn{8}{|l|}{ Housekeeping Genes ${ }^{g}$} \\
\hline AK059694 & $\begin{array}{l}\text { Ubiquitin-conjugating enzyme } \\
\text { E2 }\end{array}$ & $U B C$ & & $890 \pm 37.0$ & $853 \pm 55.7$ & 0.96 & 0.61 \\
\hline AK061988 & Ubiquitin 5 & UBQ5 & & $1,100 \pm 36.4$ & $1,216 \pm 83.0$ & 1.11 & 0.20 \\
\hline $\begin{array}{l}\text { AK072502 } \\
\text { AK100267 }\end{array}$ & $\begin{array}{c}\text { Tubulin beta-4 chain } \\
\text { Actin1 }\end{array}$ & $\begin{array}{l}\beta-T U B \\
A C T 1\end{array}$ & & $\begin{array}{l}92.5 \pm 12.5 \\
700 \pm 33.4\end{array}$ & $\begin{array}{l}76.8 \pm 11.6 \\
693+39.9\end{array}$ & $\begin{array}{l}0.83 \\
0.99\end{array}$ & $\begin{array}{l}0.36 \\
0.91\end{array}$ \\
\hline AK061464 & $\begin{array}{l}\text { Eukaryotic elongation factor } \\
\text { 1-alpha }\end{array}$ & $e E I-1 a$ & & $18,334 \pm 0.0$ & $18,334 \pm 0.0$ & 1.00 & 0.88 \\
\hline
\end{tabular}

aRaw counts. Data from NR16 and NR31 were combined $(n=6)$ and normalized to eEl-1 $\alpha$.

${ }^{\mathrm{b}} P$-value is from a two-tailed, paired $t$-test.

'Expression profiling of genes related to starch synthesis with tissue specificity as determined previously 51$]$.

${ }_{\mathrm{d}, \mathrm{e}, \mathrm{f}} \mathrm{C} 3$ photosynthesis genes [52], rice carbon assimilation SUT genes [53] and nitrogen metabolism genes [52].

gHousekeeping genes represent genes with stable expression across all genotypes and were determined previously [54].

h,iNative rice leaf AGPase large and small subunits respectively. 
transgene positive and negatives for each of the two events). On average each sample yielded $580 \mathrm{Mb}$ of sequence with approximately $12,500,000$ total $50 \mathrm{bp}$ reads generated from each cDNA library. The average per base sequence quality Phred scores from a RNA sample was 37.1 , indicating high sequence quality. Linear counts were normalized to eukaryotic elongation factor-1alpha $(e E l-1 \alpha)$ and correlations between biological replicates for both transgene positive and negative genotypes had an $r^{2}>0.9$ for the 21,000 recognized genes. Expression of the native leaf AGPase small subunit, AGPS2a, was approximately $1 / 120^{\text {th }}$ that of the $B t 2$ transgene and the native leaf large subunit, $A G P L 3$, was $1 / 20^{\text {th }}$ that of the Sh $2 r 6 h$ s transgene (Table 2). Besides the transgenes, the only other leaf starch synthesis gene with a significant difference in expression between positive and negative plants was starch synthase II-B (SSIIb), which was upregulated in transgene positive plants (Table 2).

Functional annotation clustering identified 3 clusters of highly up-regulated genes and 6 clusters of highly down-regulated genes in lines over expressing leaf starch biosynthesis (Table 3). Groups that were both up and down regulated include transcripts associated with iron and metal binding proteins and protein kinases. An up-regulated functional group that was not found to also be down-regulated was associated with ribosomal proteins and protein biosynthesis Additional down-regulated groups also associated with protein metabolism were protein transport and localization and amino acid binding.

\section{Enzyme activity and leaf starch levels}

Total AGPase enzyme activity in leaf tissue was analyzed in NR6, NR16, and NR31 homozygous transgene positive and negative sisterlines at varying concentrations of negative regulator, $\mathrm{Pi}$ (Figure $3 \mathrm{~A}$ ). In each event, AGPase enzyme activity of the positive line trended higher than that of the negative sister-line. Data were combined for homozygous positive and negative lines. At $0 \mathrm{mM} \mathrm{Pi}$, enzyme activity was highest and transgenes positives were higher in total AGP activity by $19 \%$. This trend remained throughout all concentrations, with positive transgenic lines with enzyme activity significantly higher at $0.5 \mathrm{mM}$ and $4 \mathrm{mM}$ Pi. No differences were seen in phosphate inhibition between the enzyme extracted from transgenes positive and negative plants. However, AGPase activity results were consistent with northern blot and RNA sequencing data, which demonstrates that the Sh2R6HS and BT2 proteins were expressed in leaf tissue.

Leaf starch was measured on fully expanded leaves collected from the four leaf stage at the end of the light period. All transgenes positive plants were higher in leaf starch compared to their negative sister lines (Figure 3B). Plants over expressing AGPase had a 31\% increase in leaf starch ( $p$-value $>0.01$ ) near the end of the day (Figure 3B). Lines negative for the transgenes had starch levels similar to starch levels of the 'Nipponbare' varietal control (data not shown).

\section{Effect of the Sh2r6hs and Bt2 transgenes on photosynthetic rates}

Photosynthetic $\mathrm{CO}_{2}$ fixation rates were measured on NR16 and NR31 on flag leaves at mid-day and throughout the photoperiod (Table 4). There was no difference between morning or afternoon measurements, therefore data represent photosynthetic and gas exchange measurements taken throughout the photoperiod of a single day shortly after plants reached anthesis. Photosynthetic rates were not significantly different between AGPase transgene
Table 3: Functional annotation gene clustering of highly up-regulated and downregulated genes in response to over-expression of AGPase in leaves ${ }^{\text {a }}$

\begin{tabular}{|c|c|c|}
\hline Functional Group of Differentially Expressed Genes & No. genes & $P$-value ${ }^{\text {b }}$ \\
\hline \multicolumn{3}{|l|}{ Up-regulated by leaf AGPase transgene expression } \\
\hline \multicolumn{3}{|l|}{ Cluster 1} \\
\hline Ribosomal protein & 3 & 0.07 \\
\hline Non-membrane-bounded organelle & 4 & 0.14 \\
\hline \multicolumn{3}{|l|}{ Cluster 2} \\
\hline lon binding & 6 & 0.52 \\
\hline Transition metal ion binding & 5 & 0.48 \\
\hline Iron ion binding & 4 & 0.09 \\
\hline \multicolumn{3}{|l|}{ Cluster 3} \\
\hline Phosphate metabolic process & 5 & 0.38 \\
\hline Protein tyrosine kinase activity & 3 & 0.03 \\
\hline ATP binding & 4 & 0.74 \\
\hline \multicolumn{3}{|l|}{$\begin{array}{l}\text { Down-regulated by leaf AGPase transgene } \\
\text { expression }\end{array}$} \\
\hline \multicolumn{3}{|l|}{ Cluster 1} \\
\hline Amino acid binding & 3 & 0.01 \\
\hline Kinase & 8 & 0.01 \\
\hline \multicolumn{3}{|l|}{ Cluster 2} \\
\hline Intracellular protein transport & 3 & 0.10 \\
\hline Cellular protein localization & 3 & 0.10 \\
\hline \multicolumn{3}{|l|}{ Cluster 3} \\
\hline Integral to membrane & 6 & 0.10 \\
\hline Transmembrane & 4 & 0.62 \\
\hline \multicolumn{3}{|l|}{ Cluster 4} \\
\hline Kinase & 8 & 0.01 \\
\hline Serine/threonine-protein kinase & 6 & 0.11 \\
\hline Phosphorylation & 8 & 0.17 \\
\hline ATP binding & 10 & 0.62 \\
\hline \multicolumn{3}{|l|}{ Cluster 5} \\
\hline Electron carrier activity & 3 & 0.79 \\
\hline Transition metal ion binding & 7 & 0.92 \\
\hline \multicolumn{3}{|l|}{ Cluster 6} \\
\hline Zinc & 3 & 0.72 \\
\hline Zinc ion binding & 5 & 0.77 \\
\hline Metal ion binding & 9 & 0.91 \\
\hline
\end{tabular}

aGene lists consisting of all genes found to be significantly up or down regulated at $P$-value $<0.01$ with two-tailed, equal variance t-tests were uploaded into the DAVID Functional Annotation Tool where they were clustered based on gene similarity. There were 54 up-regulated and 84 down-regulated genes included in analysis.

${ }^{\mathrm{b}}$ EASE score $P$-values were generated during DAVID analysis and are a more conservative form of Fisher Exact $P$-values.

homozygote positive and negative sister-lines. However, transgenes positive transgenic plants were significantly lower in transpiration and stomatal conductance (Table 4).

\section{Plant growth and yield analysis}

NR6, NR16, and NR31 were the transgenic events with the highest transgene expression levels and were therefore advanced for a $\mathrm{T}_{3}$ yield trial (Figure 4). A paired and randomized yield trial was conducted under 600 PAR growth conditions. Similar trends were observed between events, therefore data was combined. There was no difference between AGP transgenes positive or negative lines for days to anthesis or chlorophyll at anthesis, with negative lines flowering 86 days after planting and chlorophyll levels at 45 . AGP transgene negative plants were significantly shorter $(6 \%)$ and measured $38 \mathrm{~cm}$ tall. Seed weight per plant was not significantly different with AGP transgene negative plants having 2.9 


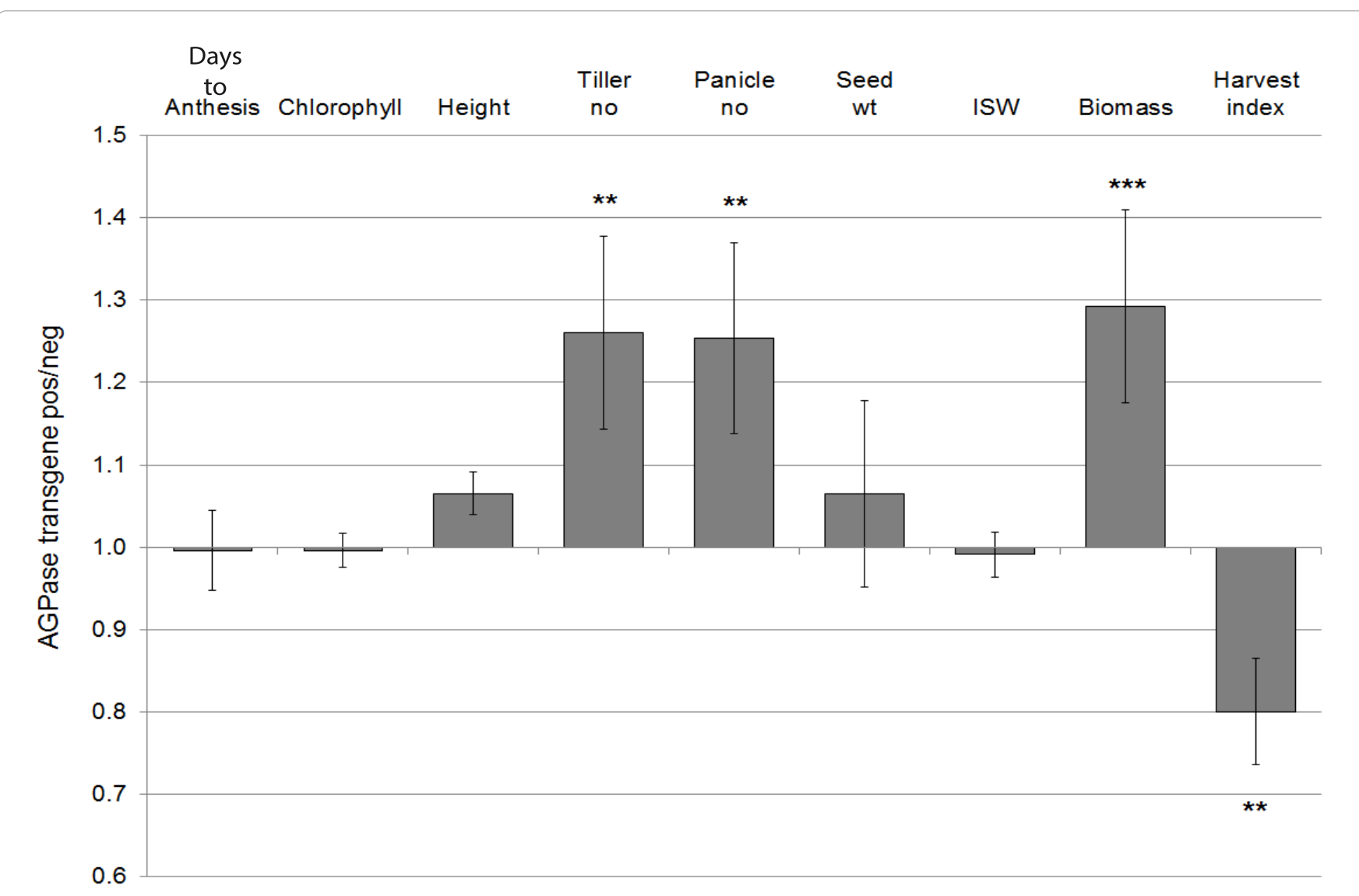

Figure 4:Influence of the Sh2r6hs and Bt2 transgenes on $\mathrm{T}_{3}$ plant phenotype. All transgene positive (pos) and negative (neg) plants were paired within genotypesto give $n=12-15$. ISW represents individual seed weight. Harvest index is the ratio of seed weight to total plant biomass.

${ }^{*},{ }^{* *},{ }^{* *}$ Homozygote transgene positive is significantly different from homozygote negative sister-line at $\alpha<0.05,0.01$, or 0.001 respectively using a two-tailed, paired $t$-test.

Table 4: Photosynthetic and gas exchange measurements for rice lines over expressing starch biosynthesis in leaves ${ }^{\mathrm{a}}$.

\begin{tabular}{|c|c|c|c|c|}
\hline & $\begin{array}{l}\text { Photosynthesis } \\
\left(\mu \mathrm{mol} \mathrm{CO} \mathrm{m}^{-2} \mathrm{~s}^{-1}\right)\end{array}$ & $\begin{array}{c}\text { Transpiration } \\
\left(\mathrm{mmol} \mathrm{H}_{2} \mathrm{O} \mathrm{m}^{-2} \mathrm{~s}^{-1}\right)\end{array}$ & $\begin{array}{c}\text { Stomatal } \\
\text { Conductance } \\
\left(\mathrm{mmol} \mathrm{H}_{2} \mathrm{O}\right. \\
\left.\mathrm{m}^{-2} \mathrm{~s}^{-1}\right)\end{array}$ & n \\
\hline $\begin{array}{l}\text { AGPase Transgene } \\
\text { Negative }\end{array}$ & $11.91 \pm 0.76$ & $4.06 \pm 0.15$ & $166.1 \pm 10.0$ & 15 \\
\hline $\begin{array}{l}\text { AGPase Transgene } \\
\text { Positive }\end{array}$ & $10.69 \pm 0.90$ & $3.49 \pm 0.19$ & $131.8 \pm 10.3$ & 14 \\
\hline $\begin{array}{l}\text { Positive/negative } \\
\text { ratio }\end{array}$ & 0.90 & 0.86 & 0.79 & \\
\hline$P$-value & 0.30 & 0.03 & 0.02 & \\
\hline
\end{tabular}

aData represent means of measurements collected from NR16 and NR31 lines throughout the photoperiod \pm standard error. Photosynthetic $\mathrm{CO}_{2}$ fixation was measured on the top flag leaf of ${ }_{3}$ plants at 1-3 DAF.

${ }^{\mathrm{b}}$ Two-tailed $p$-value is from a paired $t$-test.

grams, although plants over -expressing AGPase trended 9\% higher (3.2 g) (Figure 4). This is attributed to increase in seed number, as individual seed weight was unchanged between genotypes (18.5mg). AGP transgene negative plants had 19 panicles, 22 tillers, and $15 \mathrm{~g}$ plant biomass. Each of these traits was significantly increased in the homozygous positive group by $25-30 \%$ (Figure 4 ).

\section{Discussion}

Grain yield is dependent upon efficient allocation of photoassimilates, with growth potential of plant organs being largely driven by relative strength of different source and sink tissues [3,4]. Increasing plant yield through increases in sink strength such as by increasing seed starch biosynthesis has been the topic of much research $[5,6]$, however fewer studies have focused upon leaf starch biosynthesis. Here we examine the role that leaf starch plays in rice growth by over expressing AGPase in rice leaves.

In this study Sh2r6hs and Bt2 were over-expressed in rice leaves under control of the native rice $R B C$ green tissue-specific promoter. The transgenes were selected for transformation due to high sequence similarity to the native genes and for the genetic alterations found in Sh2r6hs [29,30]. For all tested events, progeny test data indicate single locus inheritance (Table 1). Northern blot and RNA-seq results indicate that both transgenes were actively transcribed into mRNA (Figure 2 and Table 2). RNA-seq was better able to differentiate between native gene and transgene isoforms of AGPase transcripts compared to northern blot analysis. RNA-seq also indicated that the 
transgenes were expressed at high levels relative to native leaf starch biosynthetic genes (Table 2). Additionally, increased total AGPase enzyme activity in leaf extracts from transgenes positive relative to control leaves indicate that $S H 2 R 6 H S$ and $B T 2$ are actively expressed (Figure $3 \mathrm{~A}$ ) and starch assays indicate that leaf starch levels at the end of the day correspond with AGPase protein over expression (Figure 3B). While increased Sh2r6hs and Bt2 expression did not lead to very large increases in AGPase enzyme activity or leaf starch, we previously observed that over expression of Sh2r6hs in wheat seeds led to only $5 \%$ to $20 \%$ increases in seed AGPase activity [18]. The AGPase activity assay indicated that there were no changes in allosteric properties of the enzyme conferred by the $r 6$ and $h s$ alterations present in SH2R6HS. This observation is in contrast to our previous findings [18] in which over expression of SH2R6HS in seeds was found to decrease AGPase phosphate inhibition and increase heat stability. The lack of an observed difference in AGPase allosteric properties may reflect differences in AGPase subunit processing and assembly in leaves relative to seeds. Another possibility is that the transgenic maize endosperm AGPase subunits are interacting with the native rice leaf subunits to form mosaic heterotetramers, changing the allosteric properties of the enzyme. It has been demonstrated that the maize endosperm subunits, encoded by the $S h 2$ and $B t 2$ genes, have the ability to bind with the potato tuber large and small subunits [40].

It is generally assumed that AGPase's allosteric properties are key to the increased seed [30] or plant size [7,29] seen in previous studies. There have been no studies examining whether simple over expression of an unmodified AGPase in leaves impacts plant productivity. However, over expression of native $S h 2$ and $B t 2$ in corn endosperm lead to a $9 \%$ increase in starch to give a total starch content of $74 \%$ of seed composition. This led to a $15 \%$ increase in 100 -grain weight compared to the WT [41].Therefore it seems likely that over expression of native AGPase alone in leaves would be sufficient to modify plant growth.

In our experiments, elevated activity of AGPase in leaves was associated with significantly increased plant vigor (Figure 4), but did not lead to a difference in seed size. This observation may indicate that carbon metabolism in the plant is not a limiting factor in seed production. However the positive trend in overall seed weight reflects the significant increase in tiller and panicle number in plants over expressing starch biosynthesis. Therefore this trait may be of interest to cereal breeders in their efforts to increase overall seed yield.

Although we observed a positive association between elevated activity of AGPase in leaves and increased plant vigor (Figure 4), we did not observe differences in photosynthetic rates (Table 3). This observation is supported by our RNA-seq results where important photosynthetic transcripts were unchanged between transgenes positive and negative plants (Table 4). This is interesting, as increased expression of seed specific AGPase led to enhanced photosynthesis in flag leaves of wheat shortly after anthesis [19]. Photosynthesis is however a complex process, with complex regulation [42]. Although a relationship between leaf starch and photosynthesis has been observed in Arabidopsis [43], it appears that rice plant biomass may be increased without increasing the rate of photosynthesis per unit area.

It is also interesting that stomatal conductance and transpiration were significantly lower in transgene positive plants while photosynthetic rates were unchanged, though also trended lower. Several studies have shown that it is possible to uncouple the positive correlation between photosynthetic rate and stomatal conductance [44-46]. However, the pathways associated with changes in stomatal regulation are not fully understood [47]. Of course whole plant photosynthetic rates would in fact be higher in AGPase transgene positive plants given that total plant biomass was substantially increased by AGPase over expression.

RNA-seq identified 134 genes with highly significant changes in expression level. Functional annotation clustering of these genes identified several areas in plant metabolism that were previously unknown to have functions relating to starch biosynthesis. Over expression of leaf starch biosynthesis lead to transcript changes in several functional groups. Up and down regulation of transcripts for protein kinases most likely represent changes to amino acid processes and cellular signaling (Table 3). Also in support of this, ribosomal transcripts were up-regulated indicating deregulation of protein metabolism (Table 3).

Carbon metabolism is intrinsically linked with nitrogen and lipid metabolism, as they are central to whole plant growth and metabolism. However, few studies have looked directly at the relationship between leaf starch and whole plant metabolism. In attempts to increase oil production by diverting carbon from starch biosynthesis, studies have shown that altering levels of leaf starch leads to changes in oil content [48,49]. In [48] repressing AGPase activity in conjunction with increased triacylglycerate biosynthesis led to decreased leaf starch and increased oil levels in vegetative tissues. Another study shows the importance of carbohydrate supply from vegetative tissue during the dark period; both an excess leaf starch phenotype in which starch is not degraded as well as a near starchless phenotype lead to significantly decreased lipid content in seeds [49]. Along with altering oil metabolism, starch is also linked to nitrogen metabolism. A study in maize, demonstrates that lack of leaf starch leads to significant decreases in photosynthetic proteins throughout the light cycle [23]. Additionally, a study on transgenic potato with inhibited leaf and tuber AGPase activity found that a decrease in expression of major proteins in the tuber accompanied the inhibition of starch biosynthesis [50]. Together, these studies provide a glimpse into the complex nature of starch biosynthesis and its role in metabolism. Further study on the impact of starch levels on carbon and nitrogen metabolism in various tissues throughout development would provide important information regarding how starch biosynthesis impacts plant growth and would provide insight into the nature of starch metabolism and its role in source-sink regulation.

Here we report that over expression of AGPase in leaves (Figure 2 and Table 2) is associated with an enhanced plant growth phenotype under the conditions tested. The most striking observation is that plant biomass was increased $29 \%$ in transgene positive plants (Figure 4). These findings are consistent with observations in lettuce and rice in which a modified potato AGPase was over expressed in leaves. In lettuce, over expression of AGPase resulted in increased fresh weight at 8 weeks post germination and a trend of increased panicle number in rice over expressing AGPase in leaves compared to the varietal control $[25,26]$.

The results shown here indicate that leaf starch is an important factor governing plant yield. Increasing leaf starch via increased expression of AGPase in leaves results in an enhanced plant productivity phenotype. Our results indicate that it is possible to increase plant yield without detectable changes in the rate of photosynthesis per unit area. These findings provide insight into the complex nature of plant yield and 
provide insight into the potential of increasing plant yield through manipulation of leaf starch biosynthesis.

\section{Acknowledgement}

This project was supported by Bayer Crop Science, the Consortium for Plant Biotechnology Research and Agriculture and Food Research Initiative competitive grant \#2014-67014-21664 of the USDA National Institute of Food and Agriculture. The authors declare that they have no conflicts of interest

\section{References}

1. Annicchiarico $P(2002)$ Genotype $x$ environment interactions: Challenges and opportunities for plant breeding and cultivar recommendations. FAO Plant Production and Protection Paper No. 174. Food and Agriculture Organization of the United Nations, Rome.

2. Ashraf M, Akbar M, Salim M (1994) Genetic improvement in physiological traits of rice yield. Genetic improvement of field crops, Marcel Dekker Inc. New York.

3. Van Camp W (2005) Yield enhancement genes: seeds for growth. Curr Opin Biotechnol 16: 147-153.

4. Smith AM, Stitt M (2007) Coordination of carbon supply and plant growth Plant Cell Environ 30: 1126-1149.

5. Paul MJ, Foyer $\mathrm{CH}$ (2001) Sink regulation of photosynthesis. J Exp Bot 52 1383-1400.

6. Araus JL, Slafer GA, Royo C, Serret MD (2008) Breeding for yield potential and stress adaptation in cereals. Crit Rev Plant Sci 27: 377-412.

7. Smidansky ED, Martin JM, Hannah LC, Fischer AM, Giroux MJ (2003) Seed yield and plant biomass increases in rice are conferred by deregulation of endosperm ADP-glucose pyrophosphorylase. Planta 216: 656-664.

8. Ishimaru K, Hirotsu N, Kashiwagi T, Madoka Y, Nagasuga K, et al. (2008) Overexpression of a maize SPS gene improves yield characters of potato under field conditions. Plant Prod Sci 11: 104-107

9. Tuncel A, Okita TW (2013) Improving starch yield in cereals by overexpression of ADPglucose pyrophosphorylase: expectations and unanticipated outcomes. Plant Sci 211: 52-60.

10. Hannah LC (1997) Starch synthesis in the maize seed. Cellular and molecula biology of plant seed development 4: 375-405.

11. Preiss J (1997) Modulation of starch synthesis. A molecular approach to primary metabolism in higher plants, Taylor and Francis, London.

12. Espada J (1962) Enzymic synthesis of adenosine diphosphate glucose from glucose 1-phosphate and adenosine triphosphate. J Biol Chem 237: 3577 3581 .

13. Giroux MJ, Hannah LC (1994) ADP-glucose pyrophosphorylase in shrunken-2 and brittle-2 mutants of maize. Mol Gen Genet 243: 400-408.

14. Denyer K, Dunlap F, Thorbjørnsen T, Keeling P, Smith AM (1996) The major form of ADP-glucose pyrophosphorylase in maize endosperm is extraplastidial. Plant Physiol 112: 779-785.

15. Thorbjørnsen T, Villand P, Kleczkowski LA, Olsen OA (1996) A single gene encodes two different transcripts for the ADP-glucose pyrophosphorylase small subunit from barley (Hordeum vulgare). Biochem J 313 : 149-154.

16. Beckles DM, Smith AM, ap Rees T (2001) A cytosolic ADP-glucose pyrophosphorylase is a feature of graminaceous endosperms, but not of other starch-storing organs. Plant Physiol 125: 818-827.

17. Villand P, Kleczkowski LA (1994) Is there an alternative pathway for starch biosynthesis in cereal seeds? Z. Naturforsch 49c: 215-219.

18. Meyer FD, Smidansky ED, Beecher B, Greene TW, Giroux MJ (2004) The maize Sh2r6hs ADP- glucose pyrophosphorylase (AGP) large subunit confers enhanced AGP properties in transgenic wheat (Triticum aestivum). Plant Sci 167: 899-911.

19. Smidansky ED, Meyer FD, Blakeslee B, Weglarz TE, Greene TW, et al (2007) Expression of a modified ADP-glucose pyrophosphorylase large subunit in wheat seeds stimulates photosynthesis and carbon metabolism. Planta 225: 965-976.
20. Meyer FD, Talbert LE, Martin JM, Lanning SP, Greene TW, Giroux MJ (2007) Field evaluation of transgenic wheat expressing a modified ADP-glucose pyrophosphorylase large subunit. Crop Sci 47: 336-342.

21. Rösti S, Fahy B, Denyer K (2007) A mutant of rice lacking the leaf large subunit of ADP-glucose pyrophosphorylase has drastically reduced leaf starch content but grows normally. Funct Plant Biol 34: 480-489.

22. Slewinski TL, Ma Y, Baker RF, Huang M, Meeley R, et al. (2008) Determining the role of Tie-dyed1 in starch metabolism: epistasis analysis with a maize ADPglucose pyrophosphorylase mutant lacking leaf starch. J Hered 99: 661-666.

23. Schlosser AJ, Martin JM, Hannah LC, Giroux MJ (2012) The maize leaf starch mutation, agps-m1, has diminished field growth and productivity. Crop Sci 52: 700-706.

24. Greene TW, Kavakli IH, Kahn ML, Okita TW (1998) Generation of upregulated allosteric variants of potato ADP-glucose pyrophosphorylase by reversion genetics. Proc Natl Acad Sci U S A 95: 10322-10327.

25. Lee S-M, Ryu T-H, Kim S-I, Okita T, Kim D (2009) Kinetic and regulatory properties of plant ADP-glucose pyrophosphorylase genetically modified by heterologous expression of potato upreg mutants in vitro and in vivo. Plant Cell Tiss. Org Cult 96: 161-170.

26. Gibson K, Park JS, Nagai Y, Hwang SK, Cho YC, et al. (2011) Exploiting leaf starch synthesis as a transient sink to elevate photosynthesis, plant productivity and yields. Plant Sci 181: 275-281.

27. Paz M, Shou H, Guo Z, Zhang Z, Banerjee A, et al. (2004) Assessment of conditions affecting Agrobacterium-mediated soybean transformation using the cotyledonary node explant. Euphytica 136: 167-179.

28. Shaw JR, Hannah LC (1992) Genomic Nucleotide Sequence of a Wild-Type Shrunken-2 Allele of Zea mays. Plant Physiol 98: 1214-1216.

29. Smidansky ED, Clancy M, Meyer FD, Lanning SP, Blake NK, et al. (2002) Enhanced ADP-glucose pyrophosphorylase activity in wheat endosperm increases seed yield. Proc Natl Acad Sci U S A 99: 1724-1729.

30. Giroux MJ, Shaw J, Barry G, Cobb BG, Greene T, et al. (1996) A single mutation that increases maize seed weight. Proc Natl Acad Sci U S A 93: 5824-5829.

31. Greene TW, Hannah LC (1998) Adenosine diphosphate glucose pyrophosphorylase, a rate limiting step in starch biosynthesis. Physiologia Plantarum 103: 574-580.

32. Bhave MR, Lawrence S, Barton C, Hannah LC (1990) Identification and molecular characterization of Shrunken-2 cDNA clones of maize. Plant Cell 2: $581-588$

33. Allen GC, Spiker S, Thompson WF (2000) Use of matrix attachment regions (MARs) to minimize transgene silencing. Plant Mol Biol 43: 361-376.

34. Toki S (1997) Rapid and efficient Agrobacterium-mediated transformation in rice. Plant Molec Biol Reporter 15: 16-21.

35. Mortazavi A, Williams BA, McCue K, Schaeffer L, Wold B (2008) Mapping and quantifying mammalian transcriptomes by RNA-Seq. Nat Methods 5 : 621-628.

36. Huang da W, Sherman BT, Lempicki RA (2009) Systematic and integrative analysis of large gene lists using DAVID bioinformatics resources. Nat Protoc 4: 44-57.

37. Smith AM, Zeeman SC (2006) Quantification of starch in plant tissues. Nat Protoc 1: 1342-1345.

38. Rösti S, Rudi H, Rudi K, Opsahl-Sorteberg HG, Fahy B, et al. (2006) The gene encoding the cytosolic small subunit of ADP-glucose pyrophosphorylase in barley endosperm also encodes the major plastidial small subunit in the leaves. J Exp Bot 57: 3619-3626.

39. Eddy R, Hahn DT (2008) Optimizing greenhouse rice production: what is the best fertilization schedule? Purdue Methods for Rice Growth.

40. Cross JM, Clancy M, Shaw JR, Greene TW, Schmidt RR, et al. (2004) Both subunits of ADP-glucose pyrophosphorylase are regulatory. Plant Physio 135: $137-144$.

41. Li N, Zhang S, Zhao Y, Li B, Zhang J (2011) Over-expression of AGPase genes enhances seed weight and starch content in transgenic maize. Planta 233: $241-250$. 
42. Eberhard S, Finazzi G, Wollman FA (2008) The dynamics of photosynthesis Annu Rev Genet 42: 463-515.

43. Sun J, Okita TW, Edwards GE (1999) Modification of carbon partitioning photosynthetic capacity, and $\mathrm{O} 2$ sensitivity in Arabidopsis plants with low ADP-glucose pyrophosphorylase activity. Plant Physiol 119: 267-276.

44. Haake V, Zrenner R, Sonnewald U, Stitt M (1998) A moderate decrease of plastid aldolase activity inhibits photosynthesis, alters the levels of sugars and starch, and inhibits growth of potato plants. Plant J 14: 147-157.

45. Muschak M, Willmitzer L, Fisahn J (1999) Gas-exchange analysis of chloroplastic fructose-1,6-bisphosphatase antisense potatoes at different air humidities and at elevated $\mathrm{CO}_{2}$. Planta 209: 104-111.

46. Baroli I, Price GD, Badger MR, von Caemmerer S (2008) The contribution of photosynthesis to the red light response of stomatal conductance. Plant Physiol 146: 737-747.

47. Damour G, Simonneau T, Cochard H, Urban L (2010) An overview of models of stomatal conductance at the leaf level. Plant Cell Environ 33: 1419-1438.

48. Sanjaya, Durrett TP, Weise SE, Benning C (2011) Increasing the energy density of vegetative tissues by diverting carbon from starch to oil biosynthesis in transgenic Arabidopsis. Plant Biotechnol J 9: 874-883.
49. Andriotis VM, Pike MJ, Schwarz SL, Rawsthorne S, Wang TL, et al. (2012) Altered starch turnover in the maternal plant has major effects on Arabidopsis fruit growth and seed composition. Plant Physiol 160: 1175-1186.

50. Müller-Röber B, Sonnewald U, Willmitzer (1992) Inhibition of the ADPglucose pyrophosphorylase in transgenic potatoes leads to sugar-storing tubers and influences tuber formation and expression of tuber storage protein genes. The EMBO J. 11: 1229-1238.

51. Hirose T, Ohdan T, Nakamura Y, Terao T (2006) Expression profiling of genes related to starch synthesis in rice leaf sheaths during the heading period. Physiologia Plantarum 128: 425-435.

52. Malkin R, Niyogi K (2000) Photosynthesis. Biochemistry \& molecular biology of plants, American Society of Plant Biologists, Somerset, NJ, USA.

53. Aoki N, Hirose T, Scofield GN, Whitfeld PR, Furbank RT (2003) The sucrose transporter gene family in rice. Plant Cell Physiol 44: 223-232.

54. Jain M, Nijhawan A, Tyagi AK, Khurana JP (2006) Validation of housekeeping genes as internal control for studying gene expression in rice by quantitative real-time PCR. Biochem Biophys Res Commun 345: 646-651. 